\title{
ASSESSING THE BARRIERS TO THE DEVELOPMENT OF ELECTRIC VEHICLES IN THE URBAN TRANSPORT NETWORK OF VALENCIA
}

\author{
Paula Bastida-Molina ${ }^{1 *}$, David Ribó-Pérez ${ }^{1}$, Tomás Gómez-Navarro ${ }^{1}$, Elías Hurtado- \\ Pérez ${ }^{1}$ \\ ${ }^{1}$ Institute for Energy Engineering. Universitat Politècnica de València \\ *Corresponding author: paubasmo@etsid.upv.es
}

\begin{abstract}
Transport sector is responsible for around a quarter of the global $\mathrm{CO}_{2}$ emissions emitted to the atmosphere, and 50\% in the cities. Hence, the electrification of the urban transport arises as an environmental solution to cope with the worrisome climate change. Despite the environmental suitability of electric vehicles (EVs), their integration in the urban transportation network is suffering a slow process. A wide range of barriers difficult this integration regarding different areas of the urban electric transport. These barriers present interdependence among them and can be divided in five different clusters: technical, economic, environmental, social and institutional. Many of the barriers are qualitative and/or uncertain. Therefore, the authors have used the Analytic Network Process (ANP) method in this research to rank order the barriers and, based on them, the different urban electric mobility alternatives. For that, a panel of experts with different profiles (academia, private sector, policy and users) has been formed. To illustrate its feasibility and utility, the authors designed the application of the method for a flat medium city pattern. Then, it was specifically applied to the city of Valencia. The research is still in process.
\end{abstract}

Keywords: ANP, electric vehicles, barriers analysis, Valencia.

\section{Introduction}

By the end of the 20th century, climate change has turned out to be one of the most disturbing global issues, mainly motivated by the exorbitant amounts of Greenhouse Gases (GHG) sent to the atmosphere. Transport results one of the most polluting sectors, being responsible for around $25 \%$ of the global $\mathrm{CO}_{2}$ emissions, and around $50 \%$ of the cities' GHG emissions. Besides, almost 93\% of the global transport consumption in 2017 derived from oil products, whose reserves are finite. Both reasons (finite resources and environmental impact) have motivated the electrification of the transportation sector, which arises as an environmental solution.

Despite the environmental suitability of electric vehicles (EVs), their development and integration in the urban transportation network is suffering a slow process. For instance, the average market share of electric passenger cars in the European Union in 2017 was only $1.14 \%$. Several studies have tried to shed light on this problem (see section 2).

The results of the literature review reveal that the difficulties to integrate EVs in the transport system depend on a wide range of barriers. Some of them could seem the main drivers, like the accessibility of charging stations or the charging time, whereas another ones result sometimes neglected despite its importance, like the users' willingness to accept

International Symposium on the Analytic Hierarchy Process
WEB CONFERENCE DEC. 3 - DEC. 6, 2020 
driving changes. Moreover, these barriers can be grouped in different clusters, with interdependence between them and the different alternatives of transport systems.

Therefore, the study of the barriers that difficult the integration of EVs in different areas of the transport system comprises a multicriteria and multiple choice problem, where the information results most of the times incomplete and uncertain or qualitative.

Is in this context where a Multi Criteria Decision Making Method (MCDM) like the Analytic Network Process (ANP) can provide valuable information. ANP is a well-known proven tool that can cope with issues characterized by qualitative information, lack of information and complex interrelations of the elements. Hence, we have applied the method ANP to study the barriers that difficult the integration of EVs regarding different transport areas.

To prove the feasibility of the proposed method, we have applied it to a case study in Valencia city (Spain). This application has followed three different stages. Firstly, we developed a universal application. Then, we adjusted it to cope with the necessities of a specific city pattern: Mediterranean flat medium city pattern. This pattern covers all the cities with Mediterranean climatology, buildings architecture, flat orography, medium size and mature electricity distribution. Finally, we chose Valencia as a case study.

\section{Literature Review}

Other studies have applied multicriteria methods to study the barriers of implementing another types of alternative vehicles, like autonomous ones [1], fuel cell vehicles [2] or the customers' acceptance of alternative powertrain technologies [3]. However, to the best of our knowledge, no previous research has used the ANP MCDM to assess the barriers that difficult the integration of EVs in different areas of the urban mobility. Hence, our study tries to fill this gap for flat medium city patterns, specifically for Valencia city.

\section{Objectives}

The main goal of this research is to rank order the influential criteria, and the mobility alternatives accordingly, in order to inform the decision making processes of electric mobility in Mediterranean flat medium city patterns, specifically in Valencia city.

\section{Methodology}

ANP

The Analytic Network Process (ANP) is a multicriteria decision making method with the capability to deal with incomplete, uncertain and qualitative information that does not involve straight forward decisions [4]. ANP is a method proposed by Saaty that enables a framework for decision making under complex contexts. The ANP models the problem as a network with different criteria and alternatives, which group in clusters. Then, the ANP derives ratio-scale measurements to allocate weights based on ratio-scale priorities to allow trade-off analysis. The method compares the elements of the network and provides particular and aggregated values.

\section{Barriers and alternatives}

After a careful review, authors defined a list of 17 barriers divided into 5 clusters for the integration of EVs and 5 urban electric mobility alternatives, as Table 1 indicates: 
Table 1. Barriers and alternatives.

\begin{tabular}{|c|c|}
\hline Clusters & Barriers \\
\hline Technical & $\begin{array}{l}\text { - } \text { Shortage of public recharging points } \\
\text { - } \text { Batteries’ autonomy power } \\
\text { - } \quad \text { Long time recharging periods } \\
\text { - } \quad \text { Negative impact on the electrical grid of non-scheduled recharge } \\
\text { - } \quad \text { Lack of standardization in EVs' components }\end{array}$ \\
\hline Economic & $\begin{array}{l}\text { - CapEx of EVs } \\
\text { - CapEx of recharging points' structures } \\
\text { - OpEx of recharging points's structures } \\
\text { - CapEx of batteries }\end{array}$ \\
\hline Social & $\begin{array}{ll}\text { - } & \text { Lack of previous EV models } \\
\text { - } & \text { Fear of changing pre-established driving patterns } \\
\text { - } & \text { Lack of knowledge of electric mobility } \\
\end{array}$ \\
\hline Environmental & $\begin{array}{l}\text { - } \text { Finite batteries resources } \\
\text { - } \quad \text { Life cycle of the EVs' batteries } \\
\text { - } \quad \text { Residues of the EVs' batteries }\end{array}$ \\
\hline Institutional & $\begin{array}{ll}\text { - Insufficient subsidies for EVs' development } \\
\text { - } \quad \text { Insufficient traffic taxes to promote EVs }\end{array}$ \\
\hline Alternatives & $\begin{array}{l}\text { - } \quad \text { Mobility of services: ambulance, firefighters, police... } \\
\text { - } \quad \text { Freight transport } \\
\text { - } \quad \text { Public passenger transport } \\
\text { - } \quad \text { Private passenger transport } \\
\text { - } \quad \text { Private transport sharing }\end{array}$ \\
\hline
\end{tabular}

\section{Experts}

In our case, four types of experts comprise our panel, which includes academia, private companies, policy makers and users.

Academia: researches have been working in the electrification of transport for a time now. Different studies deal with both the need to decarbonize transport and how to optimally do so from technical, environmental, and social perspectives. Their insight provides expertise on how systems are designed now but also the future trends.

Private sector: vehicle manufacturers are moving fast to shift production to electric. Moreover, new companies are arising to produce elements that where not present in the fossil fuel based system such as chargers, electronic elements...

Policy makers: have expertise in the system as a whole and promote policies and plans to decarbonise the transport sector. These include municipal, regional, and national planners that manage from daily elements of mobility such as traffic management, public transport tax to strategic planning.

Users: in the transition of transport towards sustainability users will be key stakeholder as they benefit and have the right to mobility. Users will face not only technical but also social and behavioural barriers associated with an embedded tradition of individual car use.

\section{Conclusions}

Due to the nature of the study (research in progress), we cannot show still the results and conclusions. 


\section{Key References}

[1] Raj A, Kumar JA, Bansal P. A multicriteria decision making approach to study barriers to the adoption of autonomous vehicles. Transp Res Part A Policy Pract 2020;133:122-37. https://doi.org/10.1016/j.tra.2020.01.013.

[2] Zhang L, Yu J, Ren J, Ma L, Zhang W, Liang H. How can fuel cell vehicles bring a bright future for this dragon? Answer by multi-criteria decision making analysis. Int J Hydrogen Energy 2016;41:17183-92. https://doi.org/10.1016/j.ijhydene.2016.08.044.

[3] Sousa N, Almeida A, Coutinho-Rodrigues J. A multicriteria methodology for estimating consumer acceptance of alternative powertrain technologies. Transp Policy 2020;85:18-32. https://doi.org/10.1016/j.tranpol.2019.10.003.

[4] Ribó-Pérez D, Bastida-Molina P, Gómez-Navarro T, Hurtado-Pérez E. Hybrid assessment for a hybrid microgrid: A novel methodology to critically analyse generation technologies for hybrid microgrids. Renew Energy 2020;157:874-87. https://doi.org/10.1016/j.renene.2020.05.095. 